\title{
The Design Concept of Newly Developed "Mobile Chair" and Its Performance
}

\author{
Takashi Masuzawa ${ }^{1}$, Masaaki Doi ${ }^{2}$, Shigeyuki Minami ${ }^{3}$, Masaru Nakaseko ${ }^{4}$, \\ Kazunari Morimoto ${ }^{5}$, Hajimu Ikeda ${ }^{6}$, and Hiroshi Ikeda ${ }^{7}$ \\ ${ }^{1}$ Department of Electronics \& Informatics, Osaka City University, JZA00265@nifty.ne.jp \\ ${ }^{2}$ Department of Electronics \& Informatics, Osaka City University, doi@em.elec.eng.osaka-cu.ac.jp \\ ${ }^{3}$ Department of Electrical Engineering, Osaka City University, minami@elec.eng.osaka-cu.ac.jp \\ ${ }^{4}$ Department of Arts and Sciences, Osaka University of Education,nakaseko@cc.osaka-kyoiku.ac.jp \\ ${ }^{5}$ Graduate Program of Advanced Fibro-Science in Graduate School of Engineering and Science, Kyoto Institute of Technology, morix@ipc.kit.ac.jp \\ ${ }^{6}$ Graduate School of Science and Engineering, Yamagata University, hajimu.ikeda@union-services.com \\ ${ }^{7}$ Interdisciplinary Graduate School of Science and Technology, Kinki University,hiroshi.ikeda@union-services.com
}

\begin{abstract}
Electrification of a transportation device makes it possible to achieve quietness and high-performance control. Electric vehicles have been developed based on such kind of thought. Wheel Chairs might get comfortableness and excellent mobility by electrification. The conventional electric powered wheel chair, PWC, has, however, the following disadvantages due to universal functions: (1) heavy weight makes it difficult to store especially in-house use when it is not in use, (2) the design of PWC is somewhat out of place with surrounding furniture, (3) PWC cannot easily turn in a limited house space. We have made a new powered wheel chair named "mobile chair" which has excellent features solving the above-mentioned problems. This paper introduces the design and performances as well as the evaluation of the mobile chair based on a human engineering point of view.
\end{abstract}

\section{Keywords}

powered wheel chair, PWC, mobile chair, welfare vehicle

\section{INTRODUCTION}

There are so many productions of different kinds of powered wheel chairs, PWC, in the world. These are designed mostly for general purpose, so they are extremely heavy to carry for indoor use or too high power consumptions to run at high speed. Also these PWC have a lack of compatibility or harmony with other furniture and the living atmosphere. There has so far been no light weight, simple and low price and good harmony with the living space. By a mass production of such compact PWC, we named as Mobile Chair, the price is expected to be low just like a furniture chair. The Mobile chair should provide a high cost performance and high efficiency mobility for indoor use. The motor to be used is not necessarily high power like an outdoor use PWC. Mobile chair has small wheels and a smart design matching with articles of furniture without a sense of incompatibility with other installed furniture. The design is also made for all elderly people whose mobility by feet is insufficient and who don't like to use conventional PWC to be treated as a weak person or disabled person.

People's sensitivity is also an important issue to the design of such vehicles. So an evaluation of the produced
Mobile Chair was performed.

\section{THE MOBILE CHAIR}

We have designed two mobile chairs. The first mobile chair is designed as shown in Figure 1. The base plate to drive the chair is a disk with 16 small casters to minimize the pressure applied to the floor. Two motors are installed in the center of the desk with a suspension as shown in Figure 2. In order to obtain a strong grip to the floor, the 2 motors push the floor by the spring shown in Figure 2. The driving force is designed to be kept constant and not to depend on the roughness and softness of the floor. The height of the drive wheels is controlled

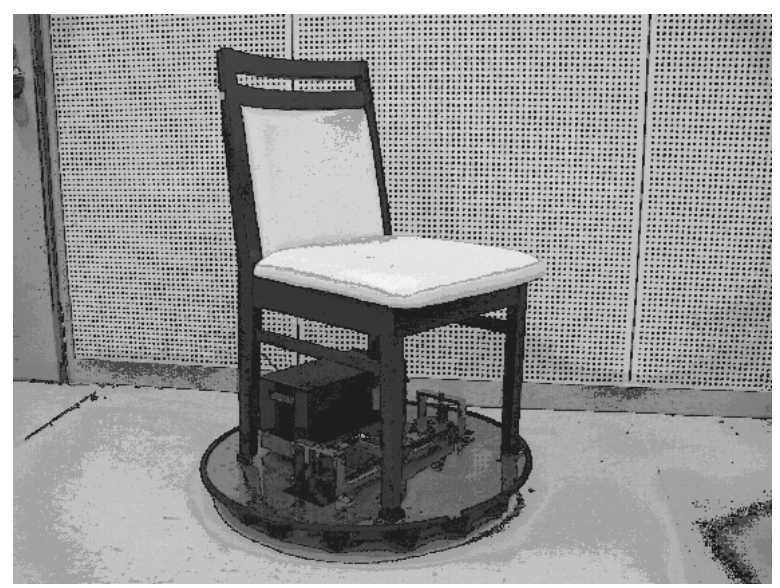

Fig. 1 A photograph of the first proto-type Mobile Chair 


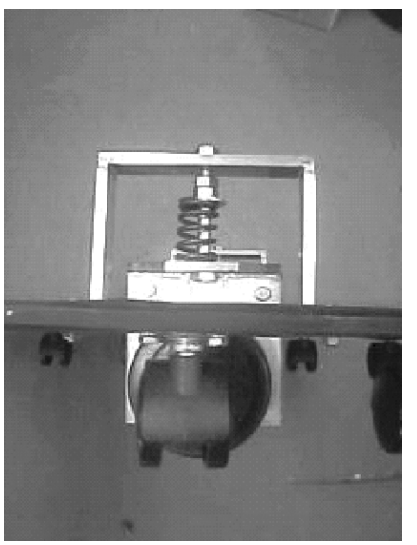

Fig. 2 A photograph of the suspension

automatically by the suspension. The chair itself, located on the driver disk plate, is not necessarily a special chair for the PWC but is just a commonly used furniture chair. It is possible to use one of the chairs set in a living room or a kitchen. Figure 3 shows a photograph of the disk from the bottom showing the location of the wheels, 2 driving motors and the suspension. The drive motors can be small enough to be able to move on the indoor floor without any bump. For this purpose, the output power of $20 \mathrm{~W}$ at maximum is used. The control of the motion is made by remote control signals sent by a person who is on the mobile chair or another person who takes care of the person on the chair. The battery installed in the mobile chair is also small, just like $24 \mathrm{~V} 7 \mathrm{Ah}$, which makes the chair possible to move for one day's motion. As the 2 motors are located in the center of the disk, it makes it possible to turn at a pinpoint without moving back or forward.

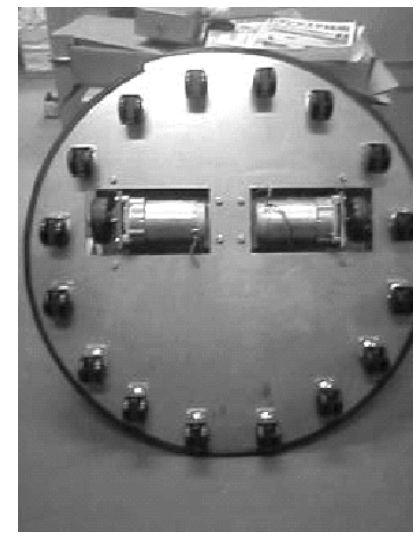

Fig. 3 A photograph of 2 motors surrounded by the wheels

We have designed another mobile chair which has a unique function of control signal input. The input signal is generated by a pair of distortion (stress) sensors located behind the chair. The stress applied to the stress sensor pushed by the person's back on the chair controls each motor to change the speed and the direction. It makes PWC's design simpler without the joystick and the armrests. Figure 4 shows an photograph of the mobile chair. The motors and battery system used for the mobile chair are also small. The specification of the No. 1 and No. 2 prototype mobile chairs is shown in Table 1.

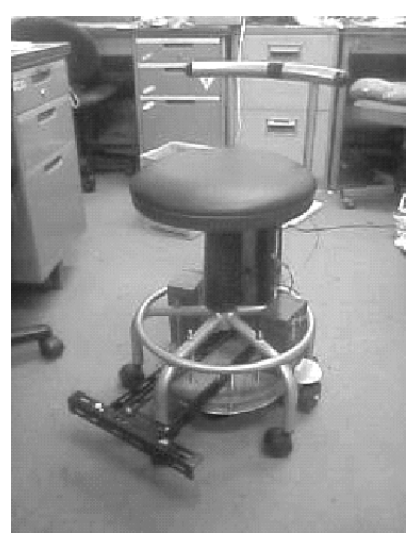

Fig. 4 A photograph of the 2nd proto-type of the Mobile Chair

Table 1 Specifications of the mobile chairs, no. 1 and no. 2

\begin{tabular}{|c|c|c|c|c|c|c|}
\hline Name & Dimension & Weight & Motor & Battery & Control & Wheels \\
\hline No. 1 & $\begin{array}{l}70 \mathrm{~cm} \text { in dia } \\
15 \mathrm{~cm} \text { high } \\
\text { (disk) }\end{array}$ & $\begin{array}{l}15 \mathrm{~kg} \\
\text { (disk system) } \\
5 \mathrm{~kg} \\
\text { (battery) }\end{array}$ & $\begin{array}{l}20 \mathrm{~W} \times 2 \\
\mathrm{PM}\end{array}$ & $24 \mathrm{~V} 7 \mathrm{Ah}$ & Joystick & $\begin{array}{l}2 \text { (drive) } \\
16 \text { (support) }\end{array}$ \\
\hline No. 2 & $\begin{array}{l}70 \mathrm{~cm} \text { high } \\
40 \mathrm{~cm} \text { in dia. }\end{array}$ & $18 \mathrm{~kg}$ (total) & $\begin{array}{l}20 \mathrm{~W} \times 2 \\
\mathrm{PM}\end{array}$ & $24 \mathrm{~V} 7 \mathrm{Ah}$ & $\begin{array}{l}2 \text { Distortion } \\
\text { sensors }\end{array}$ & $\begin{array}{l}2 \text { (drive) } \\
3 \text { (support) }\end{array}$ \\
\hline
\end{tabular}

\section{RESULTS}

We manufactured two test samples of Mobile Chair during the study term in 2004-2005.

\subsection{Mobile unit using the household chair (No. 1)}

As shown in Figure 1, this is the mobile unit assembled on the household chair.

Two driving wheels at the center of chair are held with the suspension springs (Figure 2). Twenty casters attached to the mobile unit decrease the ground pressure to prevent the unit from becoming stuck on even a carpet or tatami mat in the room (Figure 3). The operation of the mobile unit can be radio-controlled by the person on the chair or his/her home-helper.

\subsection{Movable chair (No. 2)}

The second sample is the commercial small-type chair constructed to allow it to be moved by use of electric power (Figure 4). The features of this sample are that mounting of simple parts makes it electrically driven and the distortion sensors installed on the backside and right/left sides of chair make it possible to change the forward moving direction according to the force added to them. 


\section{HUMAN ENGINEERING EVALUATION}

An evaluation of the mobile chair was performed based on human engineering. The muscle sense is measured at the waist and arms of a person on board the manufactured two prototype mobile chairs. When the person who cannot walk easily sits on a chair, he/she cannot use the large muscle of legs required to support his/her body, so that an overload signal often appears on the waist and arms. Especially, the height of the seat of a chair (the height from the floor) is important. Thus, we examined a comparison of the sense of the muscle of waist and arms at the time of sitting and standing. The analysis is focused on the dependence of (a) height of the seat of a chair and (b) load on muscle of arms for chair motion by comparing 4 different wheel chairs: a manufactured manual-type wheelchair, the commercial electric-powered wheelchair, the No. 1 and No. 2 prototype mobile chairs.

The result is shown in Figure 5. The electric potential of muscles, trapezius, is measured with the 4 types of wheel chairs and compared to each other. When the person sits in the shoulder extension or abduction, i.e., in raising his/her elbows sideward or forward, it is said that the muscle active electric potential mass of the trapezius increases and circulation inhibition occurs due to the oppressive shoulder if the shoulder abduction or extension angle is beyond $30 \bullet<$ Therefore, a great apprehension is occurred in the posture of a person on the traveling wheelchair when changes to the unnatural posture are held, so that it required a wheelchair that is able to improve the carriage of arms and maintain the comfortable traveling posture of a person to avoid secondary trouble. As shown in Figure 5, the muscle active mass of the waist is higher in the manual-type wheelchair with the shortest height of seat of the chair and the electric-powered wheelchair in order, but it is lower in the test samples with the longest height of seat of the chair. There is no difference between right and left side of the muscle active mass of the waist excluding the manual-type wheelchair. It can be said that torsion oc-

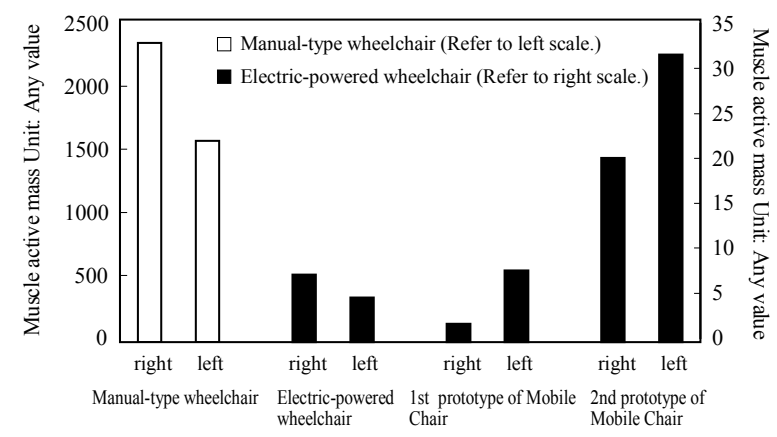

Fig. 5 Comparison of muscle active mass of trapezius (shoulder) at traveling operation between four (4) wheelchairs curs to the waist at the time of sitting and standing on the manual-type wheelchair and also the waist easily suffers a large load. There is an example that the muscle active mass of arms at the traveling operation is compared between the above four wheel chairs. The muscle electron of a manual-type wheelchair is more than 300 times the electric-powered wheelchair, and the largest muscle load is added. Since the electric-powered wheelchair and the 1st test sample of Mobile Chair are controlled by the stick gripped with the fingers, there is little load on the raised arms. The No. 2 prototype Mobile Chair can be run without using both hands. However, the control stick has to be pressed with the torsion of waist and with the line of backbone forced, so that it is necessary to move the arms to keep the correct balance in a posture of the upper half of the body at the time of traveling operation. This matter leads to the increase of muscle active mass.

From the viewpoint of total examination, a muscle load on No. 2 prototype is set within the tolerance.

\section{DISCUSSION AND CONCLUSION}

The Mobile Chair can make a clear difference against conventional wheelchairs if the area of use is limited to a room without any bumps. We found that No. 1 Mobile Chair has (a) no sense of incompatibility with other furniture installed in the room, (b) a variety of designs of Mobile Chair can be increased without taking a rainy day into consideration, and (c) the Mobile Chair can be manufactured in lightweight, stored easily, and priced down. The key-phrase is "developing and manufacturing of mobile chair, with a new idea, as an article of furniture familiar with home".

The Mobile Chair materialized in this study uses household furniture and also considered the case that a visitor who needs assistance to move can utilize the Mobile Chair prepared for visitors. The price of the Mobile chair is promised to be low. Almost all houses can be prepared for elderly people to stay or to visit. It can be stocked without a sense of incompatibility. As a result, we can expect that the Mobile Chair as a product will come into wide use and that the Mobile Chair will augment the quality of home life of people who cannot walk easily, making an actual considerable contribution. We will try to market the Mobile Chair from now on.

\section{Acknowledgement}

This Mobile Chair project was performed under financial support by Mitsubishi Foundation in 2004-2005.

(Received November 2, 2005; accepted December 12, 2005) 